\title{
Konsep Co-Management dalam Pendekatan Pengelolaan Lingkungan Mangrove di Desa Lubuk Kertang, Brandan Barat, Sumatera Utara
}

\author{
A Hadian Pratama Hamzah ${ }^{1 *}$, Trisno Anggoro², Sri Puryono ${ }^{3}$ \\ ${ }^{1,2,3}$ Pascasarjana Ilmu Lingkungan Universitas Diponegoro \\ *Correspondence email: hadi.dian@ymail.com
}

\begin{abstract}
Mangroves are one of the important coastal ecosystems that have various benefits and their uses are carried out by various stakeholders. This study aims to 1) find out and analyze the condition of mangrove resources and community beneficiaries, 2) analyze the roles and functions of each stakeholder, and 3) find out and analyze the form of co-management of mangrove ecosystem management in Lubuk Kertang Village, West Brandan, Langkat Regency. Mangrove vegetation data collection is done using the quadratic transect method; while taking socioeconomic, institutional, and interview data using survey and purposive sampling methods. Data obtained from mangrove vegetation include density, frequency, cover, and mangrove importance index. Stakeholder analysis using a matrix of interests and influences. Research shows there are 5 types of mangroves in Lubuk Kertang Village, namely Avicennia marina, Rhizophora mucronata, Rhizophora apiculata, Rhizophora stylosa and Sonneratia alba. Strategies in the context of expanding mangrove forests are with these types. Stakeholder analysis identified 16 stakeholders who were classified in 4 groups, namely subject, key players, crowd, and by standers. Mangrove management in Lubuk Kertang Village is still in the consultative stage. To improve effectiveness, management is directed at the cooperative level in the co-management spectrum with management strategies.
\end{abstract}

Keywords: mangrove, stakeholders, co-management

\section{Pendahuluan}

Kawasan pesisir merupakan daerah potongan laut dan darat yang menjadikan ekosistem wilayah pesisir rawan mengalami perubahan. Sekitar $21 \%$ populasi penduduk dunia hidup di wilayah pesisir yang merupakan zona penting dan mempunyai peran vital dalam perkembangan ekonomi di beberapa negara (Nair et al., 2012). Wilayah pesisir dan laut menjadi tumpuan strategis dan menjadi lokasi berbagai kegiatan yang saling tumpang tindih ketika sumberdaya di daratan sudah semakin menipis, seperti pelabuhan, pertanian, perikanan, permukiman dan kawasan industri yang tidak terkoordinasi dengan baik (Hadi, 2014). Berbagai macam kegiatan tersebut memberi tekanan yang berat pada lingkungan sehingga menimbulkan berbagai bencana seperti fenomena rob atau banjir pasang, abrasi, akresi, pencemaran yang menimpa hampir disepanjang pesisir Jawa menjadi indikasi terlampauinya daya dukung lingkungan (environmental carrying capacity) (Hadi, 2014).

Kawasan hutan mangrove sebagai salah satu ekosistem wilayah pesisir dan lautan sangat potensial bagi kesejahteraan masyarakat baik dari segi ekonomi, sosial, dan lingkungan hidup. Namun semakin hari semakin kritis ketersediaannya di beberapa daerah pesisir di Indonesia. Kondisi ini terjadi akibat kegiatan penebangan mangrove yang dilakukan secara berlebihan yang lahannya digunakan sebagai lahan baru untuk kegiatan pertambakan maupun tempat tinggal sehingga mangrove telah dirubah menjadi fungsi yang lain di karenakan berbagai kegiatan pembangunan. Laju kerusakan ekosistem hutan mangrove di pesisir Sumatera semakin cepat. Sehingga memberi banyak dampak bagi masyarakat terkait kondisi lingkungan, sosial dan ekonomi masyarakat disekitar kawasan hutan mangrove. Kerusakan ini sebagian disebabkan oleh tekanan penduduk dalam memanfaatkan lahan hutan mangrove untuk usaha pertambakan, ladang perkebunan dan pemukiman. Keadaan semakin parah sejak pengalihan fungsi lahan mangrove menjadi pemukiman yang dilakukan oleh warga (Irwanmay, 2004). Hasil interpretasi peta landuse wilayah pantai timur Sumatera Utara menunjukkan pada tahun 1977 terdapat sekitar 200,415 ha hutan mangrove di pesisir timur Sumatera Utara. Sebagian besar (89.093 ha atau 86,2\%) hutan mangrove tersebut berupa hutan mangrove primer dan sisanya (14.322 ha atau 13,8\%) sebagai hutan mangrove sekunder. Berdasarkan administrasi pemerintahan, sebagian besar hutan mangrove tersebut terdapat di Kabupaten Langkat dengan luas sebesar 45.909 ha (44,4\%), kemudian diikuti oleh Kabupaten Deli Serdang (21.051 ha atau 20,4\%), Kabupaten Asahan (18.785 ha atau 18,2\%) dan paling kecil luasannya pada Kabupaten Labuhan Batu (17.670 ha atau 17,1\%). (Onrizal, 2010).

Mempertimbangkan laju kerusakan hutan mengrove di Kabupaten Langkat pada tahun 2010 Dinas Kehutanan Kabupaten Langkat dan Pengelolaan Daerah Aliran Sungai. Sepakat untuk menerapkan pendekatan pengelolaan daerah kawasan hutan mangrove melalui penetapan program rehabilitasi kawasan hutan mangrove. Program ini kemudian juga diterapkan pada semua kecamatan yang memiliki kawasan hutan mangrove di Kabupaten Langkat. Dalam hal ini ada sembilan kecamatan yang memiliki kawasan hutan mangrove di Kabupaten Langkat yakni Kecamatan Babalan, Besitang Brandan Barat Gebang Pangkalan Susu, Pematang Jaya, Secanggang, Sei Lepan dan Tanjung Pura. Konsep dasar dari program rehabilitasi kawasan hutan mangrove adalah mengelola kawasan tersebut dari berbagai tekanan 
lingkungan yang dapat mempengaruhi kerusakan dan kepunahan dari berbagai spesies yang ada pada ekosistem hutan bakau sebab selain dari aktivitas rehabilitasi alam juga. (Hadian, 2020)

Melalui program rehabilitasi mangrove di Kabupaten Langkat, masyarakat di Kecamatan Brandan Barat yakni di Desa Lubuk Kertang yang mengalami kerusakan, sebelum mendapat sosialisasi rehabilitasi pada tahun 2010 telah melakukan inisiasi lokal dalam kegiatan rehabilitasi mangrove di Kecamatan Brandan Barat, masyarakat secara swadaya melakukan pengelolan lingkungan berupa pembibitan, penanaman, pemantauan, evaluasi kegiatan rehabilitasi sendiri tanpa adanya bantuan dari pemerintah untuk mengembalikan kondisi kawasan hutan mangrove di Kecamatan Brandan Barat. Setelah hampir dari tiga tahun masyarakat bekerja tepatnya pada tahun 2010 masyarakat baru mendapat sosialisasi program rehablitasi mangrove dari pihak Pemerintah Kabupaten Langkat, yakni pada tahun 2010 masyarakat dimana tahun tersebutlah masyarakat baru mendapat pembinaan dari Pemerintah setempat terkait program rehabilitasi mangrove, masyarakat dan pemerintah juga melakukan evaluasi bersama berupa perhitungan luasan tutupan mangrove dari hasil kegiatan masyarakat dari tahun 2007 yakni tepatnya tiga tahun sebelum program rehabilitasi dari Pemerintah Kabupaten Langkat tahun 2010 dilakukan. Pada kegiatan evaluasi setelah 10 tahun berupaya mengelola kawasan mangrove dimulai dari tahun 2007 jumlah luasan tutupan mangrove sebesar $1.020 \mathrm{Ha}$ dan pada saat dilakukan penghitungan luasan tutupan mangrove pada tahun 2017 diperoleh hasil kenaikan tutupan mangrove naik menjadi 1.820 Ha di Desa Lubuk Kertang Kecamatan Brandan Barat. (Nadira, 2018).

Berkat usaha bersama antara masyarakat, pemerintah dan perusahaan yakni PT. Pertamina (Persero) serta dengan kemauan keras masyarakat dalam melakukan inisiatif- inisiatif yang bersifat swadaya dalam mendorong keberhasilan rehabilitasi pada kawasan mangrove di desa mereka, sehingga terjadilah perubahan keadaan melalui luasan tutupan lahan yang meningkat, kondisi lingkungan yang tidak serusak tahun 2007, ditambah nelayan mulai dapat hasil ikan yang dirasakan meningkat. Pada 2017 lalu Desa Lubuk Kertang di Kecamatan Brandan Barat mendapat penghargaan dari Pemerintah Pusat yakni Presiden Republik Indonesia sebagai Kecamatan yang berhasil dalam upaya rehabilitasi mangrove, dalam hal ini masyarakat memiliki peran yang sangat baik dalam kegiatan rehabilitasi tersebut, seiring dengan keberhasilan Desa Lubuk Kertang mengembalikan lagi kondisi kawasan hutan mangrove penghargaan dan apresiasi dari banyak pihak diberikan pada pengelola kegiatan rehabilitasi ini. (Hadian, 2020). Berdasarkan pemaparan kondisi rehabilitasi yang dilakukan pada kawasan hutan mangrove di Desa Lubuk Kertang yang rusak parah menjadi gambaran bahwa upaya melindungi dan mengelola kawasan hutan mangrove yang terdapat pada sumberdaya pesisir bukan hanya merupakan tanggung jawab pemerintah. Masyarakat pesisir sesungguhnya juga memiliki tanggung jawab yang sama besar, mengingat kegiatan dan penghidupan mereka sehari-hari sangat bergantung pada layanan sumberdaya yang ada dan dampak dari kegiatan mereka pun cukup besar pengaruhnya terhadap sumberdaya pesisir dan lautan. Masyarakat perlu diajak untuk memutuskan metode atau cara yang digunakan dalam memanfaatkan sumberdaya pesisir dan lautan di sekitar mereka. Dengan demikian, masyarakat memegang peranan penting dalam menentukan kondisi lingkungan dan sumberdaya di sekitarnya. Gambaran kerusakan kawasan mangrove di Kabupaten Langkat dan terdapatnya satu kecamatan yang berhasil dalam melakukan kegiatan rehabilitasi menjadi sebuah gambaran bahwa hal ini dapat diteliti dari berbagai sudat pandang, salah satunya diantaranya adalah kolaborasi antara pemangku kepentingan dalam mendorong keberhasilan kegiatan rehabilitasi dapat menjadi kajian untuk menemukan fakta di lapangan terkait kecamatan lainnya di Kabupaten Langkat yang belum optimal dalam melakukan rehabilitasi sehingga dalam hal ini bentuk kegiatan rehabilitasi melalui co-management dalam mengelola dan memanfaatkan sumberdaya hutan mangrove yang juga adalah bentuk kolaborasi dari berbagai pemangku kepentingan dapat tergambarkan secara menyelutruh pada kajian penelitian ini.

Adapun dalam memaparkan hasil temuan dari penelitian ini, cangkupan pada pembahasan akan mengungkan keterkaitan antara setiap pemangku kepentingan dalam pengelolaan kawasan secara kolaboratif sehingga bentuk suatu pengelolaan sebelum dan setelah dilakukannya program rehabilitasi dapat dilihat pada kondisi lingkungan, keadaan sosial-ekonomi masyarakat yang terjadi di Desa Lubuk Kertang, Kecamatan Brandan Barat. Langkat. Adapun penelitiaan ini memiliki tujuan yakni Mengetahui dan menganalisis kondisi sumber daya mangrove dan masyarakat pemanfaat mangrove Desa Lubuk Kertang, Kabupaten Langkat, Menganalisis peran dan fungsi dari masing-masing pemangku kepentingan, Mengetahui dan menganalisis bentuk co-management terhadap pengelolaan ekosistem mangrove Desa Lubuk Kertang, Kabupaten Langkat.

\section{Metode}

Jenis data yang digunakan adalah Pengumpulan data primer dilakukan melalui pengamatan langsung (observasi) di lapangan, dengan melakukan pengukuran vegetasi mangrove, wawancara langsung dengan masyarakat lokal dan instansi terkait. (1) Data primer yaitu data yang diperoleh langsung melalui pertanyaan yang meliputi : karakteristik responden, persepsi responden tentang pengelolaan kawasan, tingkat kepentingan dalam pengelolaan dan tingkat pengaruh dalam pelaksanaan program kolaborasi manajemen dalam pengelolaan. (2) Data sekunder yaitu data yang diperoleh dari tinjauan kepustakaan melalui literatur dan jurnal-jurnal. Populasi yang digunakan adalah pengunjung 
kondisi kawasan mangrove ataau obejek yang dieliti di Lubuk Kertang Kabupaten Langkat, sedangkan sampel yang digunakan adalah pengukuran pasrtisipasi masyarakat dalam manajemen kawasan sebanyak 200 responden. Data dikumpulkan melalui instrumen penelitian berupa kuesioner sehingga dan tabulasi daftar pertanyaan pada saat melakukan interview mendalam tentang peran dan tingkat partisipasi. Data di sajikan dalam bentuk deskripsi dan hasil pengolahan data dari penyebaran kuesioner diolah dengan menggunakan tabulasi.

\section{Hasil}

Ekosistem mangrove merupakan sekumpulan vegetasi pantai tropis, yang didominasi oleh beberapa spesies pohon mangrove yang mampu tumbuh dan berkembang pada daerah pasang surut. Ekosistem mangrove banyak ditemukan pada pantai-pantai yang dangkal, daerah estuaria, teluk, delta dan daerah pantai yang terlindung. Ekosistem mangrove di Desa Lubuk Kertang terdapat di daerah sekitar delta muara. Akibat pembukaan lahan tambak udang maupun bandeng yang semakin meningkat pada tahun 1970 luas hutan mangrove di Desa Lubuk Kertang hanya tinggal sekitar 1.070 Ha dari 3.274 Ha. Seiring dengan kesadaran masyarakat yang semakin meningkat akan pentingnya mangrove, saat ini kondisi mangrove di Desa Lubuk Kertang kembali semakin baik dan luasnya saat ini mencapai 1.820 Ha pada pengukuran tahun 2017. Secara umum mangrove di Desa Lubuk Kertang Brandan Barat hidup pada salinitas 34 - 35 permil. Suhu rata-rata di ekosistem mangrove berkisar antara 29- 30 oC. Nilai pH rata-rata yang didapat pengukuran pada 3 stasiun berkisar dari 6,8 - 7,45. Keadaan ini secara umum mendukung untuk pertumbuhan mangrove. Vegetasi ekosistem mangrove di Desa Lubuk Kertang diperoleh 5 jenis mangrove sejati antar lain Avicennia marina, Rhizophora stylosa, Rhizophora mucronata, Rhizophora apiculata, dan Sonneratia alba (Tabel 1). Berdasarkan hasil pengamatan, di luar transek pengamatan dan informasi dari masyarakat

Tabel 1

Komposisi jenis mangrove yang didapatkan

\begin{tabular}{|c|c|c|c|c|}
\hline \multirow{2}{*}{ No. } & \multirow{2}{*}{ Nama Spesies } & \multicolumn{3}{|c|}{ Stasiun } \\
\hline & & Tepi pantai & Tambak & Muara sungai \\
\hline 1 & Rhizophora stylosa & $\sqrt{2}$ & $\sqrt{ }$ & 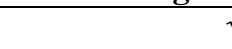 \\
\hline 2 & Rhizophora apiculata & $\sqrt{ }$ & $\sqrt{ }$ & 1 \\
\hline 3 & Rhizophora mucronata & - & $\sqrt{ }$ & \\
\hline 4 & Sonneratia alba & $\sqrt{ }$ & $\sqrt{ }$ & 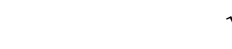 \\
\hline 5 & Avicennia marina* & - & - & . \\
\hline
\end{tabular}

Keterangan : $\sqrt{ }=$ ditemukan ; - = Tidak ditemukan ; * = ditemukan di luar transek

Sumber: data diolah

Ekosistem mangrove di Desa Lubuk Kertang merupakan satu dari beberapa ekosistem mangrove yang ada di Kabupaten Langkat yang masih relatif baik kondisinya sehingga menjadi alasan untuk dijadikan sebagai lokasi penelitian. Rata-rata lokasi mangrove di Desa lainnya berada disekitar lahan tambak penduduk. Mangrove di Desa Lubuk Kertang adalah mangrove hasil restorasi yang dilakukan selama lebih dari 30 tahun, sehingga perkembangannya sekarang ini hampir menyerupai ekosistem mangrove asli. Nilai Indeks Nilai Penting (INP) merupakan nilai yang digunakan untuk mengetahui apakah suatu jenis mangrove mempunyai pengaruh atau peranan yang besar terhadap ekosistem mangrove tersebut. Nilai INP diperoleh dari total penjumlahan kerapatan relatif, penutupan relatif dan frekuensi relatif. Menurut Bengen (2002) nilai penting suatu jenis berkisar antara 0\% dan 300\%. Spesies Rhizophora stylosa mempunyai pengaruh yang paling besar karena memiliki penyebaran paling luas di ekosistem mangrove Desa Lubuk Kertang (Tabel 2). Jenis Rhizophora sp. banyak mendominasi ekosistem mangrove di Desa Pasarbanggi dikarenakan adanya faktor substrat lumpur berpasir, dimana jenis Rhizophora sp. dapat tumbuh dan berkembang dengan baik pada jenis substrat ini (Bengen 2002; Gunarto 2004; Setyawan dan Winarno 2006). Pada dasarnya jenis Rhizophora sp. sering kali berkembang pada daerah intertidal yang luas, memiliki tingkat penyebaran yang luas dan mudah tumbuh.

Tabel 2

Sebaran Kondisi Vegetasi Mangrove Di Desa Lubuk Kertang, Brandan Barat.

\begin{tabular}{|c|c|c|c|c|c|}
\hline \multirow[b]{2}{*}{ Stasiun } & \multirow[b]{2}{*}{ Spesies } & \multicolumn{4}{|c|}{ Nilai } \\
\hline & & $\begin{array}{c}\text { Kerapatan } \\
\text { Relatif (Rdi) }\end{array}$ & $\begin{array}{c}\text { Frekuensi } \\
\text { Relatif (RFi) }\end{array}$ & $\begin{array}{c}\text { Penutupan } \\
\text { Relatif (Rci) }\end{array}$ & $\begin{array}{l}\text { Indeks Nilai } \\
\text { Penting (INP) }\end{array}$ \\
\hline \multirow{3}{*}{1} & Rhizophora stylosa & 76.47 & 50.00 & 38.91 & 165.38 \\
\hline & Rhizophora apiculata & 19.61 & 33.33 & 32.37 & 85.31 \\
\hline & Sonneratia alba & 3.92 & 16.67 & 28.71 & 49.30 \\
\hline \multirow{3}{*}{2} & Rhizophora stylosa & 83.33 & 33.33 & 31.08 & 147.74 \\
\hline & Rhizophora apiculata & 3.33 & 15.14 & 15.14 & 33.61 \\
\hline & Rhizophora mucronata & 8.33 & 11.11 & 15.14 & 34.58 \\
\hline
\end{tabular}


A Hadian Pratama Hamzah et al, Konsep Co-Management dalam Pendekatan Pengelolaan Lingkungan Mangrove di Desa Lubuk Kertang, Brandan Barat, Sumatera Utara

\begin{tabular}{llrrrr}
\hline & & & & & \\
& & & & 32.74 & \\
\\
& Sonneratia alba & 5.00 & 33.33 & 31.07 \\
& Rhizophora stylosa & 86.67 & 42.86 & 32.48 & 162.01 \\
& Rhizophora apiculata & 13.33 & 40.95 & 40.95 & 95.23 \\
& Sonneratia alba & 1.67 & 14.29 & 26.57 & 42.53 \\
\hline
\end{tabular}

Sumber: data diolah

\section{Konsep Collaborative-Managemeent Pada Ekologi Kawasan Mangrove}

Berdasarkan spektrum co-management yang disusun oleh Adrianto (2007) dalam pengelolaan sumber daya, saat ini pengelolaan mangrove di Desa Pasarbanggi berada pada tahap konsultatif. Pada tahap ini pemerintah mulai banyak melakukan dialog dan diskusi dengan para pelaku kepentingan terhadap sumber daya mangrove. Namun dalam kegiatan penyusunan perencanaan, pengorganisasian, pengawasan dan evaluasi dari masing-masing pemangku kepentingan terbatas hanya pada pemerintah dan pelaksanaan program belum menyeluruh kepada para pemangku kepentingan (Tabel 3). Cenderung dalam pelaksanaan program masih berjalan sendiri-sendiri dan kurang kerjasama antar instansi yang berkepentingan maupun dengan pemangku kepentingan lain. Pertukaran informasi masih bersifat sepihak karena komunikasi dan koordinasi antara pemerintah dengan pemangku kepentingan lain masih kurang.

Tabel 3

Kajian pengelolaan mangrove di Desa Lubuk Kertang, Brandan Barat.

\begin{tabular}{|c|c|c|c|}
\hline Kriteria & Kondisi di lapangan & Kondisi ideal yang diharapkan & Strategi manajemen \\
\hline $\begin{array}{l}\text { Penyusunan rencana } \\
\text { pengelolaan mangrove }\end{array}$ & $\begin{array}{l}\text { Hanya dari pihak pemerintah } \\
\text { dan tidak semua pemangku } \\
\text { kepentingan dari pihak } \\
\text { masyarakat dilibatkan dalam } \\
\text { menyusun } \\
\text { perencanaan }\end{array}$ & $\begin{array}{l}\text { Melibatkan semua pemangku } \\
\text { kepentingan }\end{array}$ & $\begin{array}{l}\text { Mengidentifikasi seluruh } \\
\text { pemangku kepentingan }\end{array}$ \\
\hline Pelaksanaan program & $\begin{array}{l}\text { Kerjasama hanya melibatkan } \\
\text { sebagian masyarakat dan tidak } \\
\text { menyeluruh pada tiap } \\
\text { pemangku kepentingan }\end{array}$ & $\begin{array}{l}\text { Kerjasama antara pemerintah dan } \\
\text { masyarakat }\end{array}$ & $\begin{array}{l}\text { Membuat sebuah } \\
\text { kesepakatan sesuai dengan } \\
\text { kapabilitas masing-masing } \\
\text { pemangku } \\
\text { kepentinagn }\end{array}$ \\
\hline Pengorganisasian & $\begin{array}{l}\text { Komunikasi dan koordinasi } \\
\text { tidak/lama terjadi baik dari } \\
\text { pemerintah ke masyarakat dan } \\
\text { juga sebaliknya, karena belum } \\
\text { adanya lembaga pengelola } \\
\text { mangrove } \\
\text { yang menaungi semua } \\
\text { pemangku kepentingan }\end{array}$ & $\begin{array}{l}\text { Terjadi komunikasi dan koordinasi antar } \\
\text { pemangku kepentingan secara kontinu }\end{array}$ & $\begin{array}{l}\text { Membuat lembaga } \\
\text { pengelola khusus mangrove } \\
\text { yang terdiri dari berbagai } \\
\text { pemangku kepentingan }\end{array}$ \\
\hline $\begin{array}{l}\text { Pengawasan program } \\
\text { dan evaluasi }\end{array}$ & $\begin{array}{l}\text { Hanya dari pihak pemerintah } \\
\text { dan tidak semua pemangku } \\
\text { kepentingan dilibatkan dalam } \\
\text { kegiatan pengawasan } \\
\text { dan evaluasi }\end{array}$ & $\begin{array}{l}\text { Melibatkan semua pemangku } \\
\text { kepentingan }\end{array}$ & $\begin{array}{l}\text { Menetapkan forum } \\
\text { pertemuan rutin bagi semua } \\
\text { pemangku kepentingan } \\
\text { terkait pengawasan dan } \\
\text { evaluasi }\end{array}$ \\
\hline
\end{tabular}

Sumber: data olahan

Pemerintah selaku penentu kebijakan utama tidak dapat mengabaikan keterlibatan kelompok pemangku kepentingan dalam penyusunan rencana pengelolaan. Pemangku kepentingan terutama dari masyarakat sangat dibutuhkan perannya sebagai informan mengenai sumber daya mangrove. Selain itu, masyarakat merupakan pihak yang paling mendapatkan manfaat dari pengelolaan mangrove sehingga masyarakat perlu dilibatkan dalam penyusunan rencana pengelolaan. Banyaknya pemangku kepentingan yang memanfaatkan mangrove sehingga diperlukan strategi manajemen dengan mengidentifikasi terhadap para pemangku kepentingan terhadap mangrove sehingga proses penyusunan rencana pengelolaan dapat melibatkan para pemangku kepentingan tersebut. Adapun indikator dari keberhasilan dapat terlihat dari perencanaan pengelolaan mangrove yang dapat mengakomodir kepentingan dari tiap pemangku kepentingan dengan tetap memperhatikan kelestarian mangrove. Pelaksanaan program yang masih melibatkan sebagian masyarakat membuat banyak para pemangku kepentingan yang merasa belum diikutkan dalam kegiatan pengelolaan mangrove. Keterlibatan semua pemangku kepentingan dapat membantu pelaksanaan program pengelolaan sesuai dengan kapabilitas masing-masing pemangku kepentingan. Hal ini dapat dibuat suatu bentuk kesepakatan tertulis sesuai dengan kapabilitas masing-masing pemangku kepentingan baik dari pemerintah maupun masyarakat sehingga dapat diketahui peran dari masing-masing pemangku kepentingan dalam pengelolaan mangrove. 
Indikator dari keberhasilan dapat dilihat dari pelaksanaan peran dari masing- masing pemangku kepentingan. Masih lemahnya koordinasi dan komunikasi antar pemangku kepentingan baik dari pemerintah ke masyarakat maupun sebaliknya membuat koordinasi antar pemangku kepentingan masih kacau dan sering terjadi tumpang tindih kebijakan. Peristiwa tumpang tindih kebijakan dan kurang terkoordinasinya kegiatan pelaksanaan dalam pengelolaan mangrove sudah sering terjadi. Sebagai contoh, Saat DKP melakukan kegiatan pelebaran sungai dengan jalan menebang pohonpohon mangrove di sekitar sungai kurang melakukan sosialisasi terlebih dahulu dan tidak melakukan koordinasi dengan instansi pemerintah lain yang terkait dengan pengelolaan mangrove. Selain kegiatan tersebut, seringkali diadakan masing-masing instansi melakukan kegiatan penanaman mangrove pada daerah tertentu secara sendiri-sendiri. Strategi dengan membuat lembaga pengelola khusus mangrove yang terdiri dari para pemangku kepentingan terhadap mangrove diharapkan dapat meminimalkan tumpang tindih kebijakan antar pemangku kepentingan. Selain itu dengan adanya lembaga pengelola, informasi, kegiatan, dan kerjasama antar pemangku kepentingan dapat dikontrol dan dipantau satu sama lain.

Belum adanya suatu lembaga pengelola yang terdiri para pelaku kepentingan menjadi kendala dalam pengelolaan mangrove di Kabupaten Langkat, khususnya mangrove Desa Lubuk Kertang. Nobel (2005) menyatakan bahwa dalam pendirian sebuah institusi pengelolaan suatu ekosistem sumber daya harus memiliki 6 kriteria khusus agar terlaksana sesuai dengan prinsip co- management. Enam (6) prinsip dalam membentuk dan menilai institusi baru guna mengelola mangrove secara co-management antara lain organisasi yang interaktif, kontrol lokal, dukungan masyarakat, proses yang terencana, keragaman anggota, prinsip holism (pengkajian semua aspek). Semua prinsip memiliki keterikatan dan mendukung satusama lain. Pembentukan lembaga pengelola tersebut bersifat formal diantara para pemangku kepentingan namun dalam bekerjarnya dapat bersifat non-formal. Di dalam lembaga pengelola tersebut terdapat semua pemangku kepentingan baik pemerintah, swasta, dan masyarakat yang dilibatkan dalam pengelolaan ekosistem mangrove sehingga semua pemangku kepentingan dapat memiliki informasi dan berpartisipasi dalam pengelolaan ekosistem mangrove.

Dalam pembentukan lembaga pengelola diperlukan keterlibatan pemerintah daerah yang dalam hal ini di wakili oleh BAPPEDA dalam lembaga pengelola tersebut karena terkait pemangku kebijakan dan penengah dalam perencanaan ekosistem sesuai dengan konsep kriteria institusi co-management yang disusun oleh Nobel (2005) (White (1994) in Wijanarko (2016)). Adanya lembaga pengelola, kontrol peran dari masing-masing pemangku kepentingan dapat lebih mudah dilakukan serta berjalannya saling tukar informasi mengenai sumberdaya mangrove dari para pemangku kepentingan (Tabel 4).

Tabel 4

Peran pemangku kepentingan dalam lembaga pengelola

\begin{tabular}{|c|c|c|c|}
\hline No & Instansi & Kuadran & Peran dan Tanggungjawab yang Diharapkan dalam Lembaga Pengelola \\
\hline \multirow[t]{2}{*}{1} & Dinas & 2 & 1. Memfasilitasi rehabilitasi ekosistem mangrove \\
\hline & Kehutanan & & $\begin{array}{l}\text { 2. Pengembangan program pengelolaan hutan lestari dan penyusunan aturan adat } \\
\text { mengenai mangrove }\end{array}$ \\
\hline \multirow[t]{3}{*}{2} & DKP & 2 & 1. Membuat peraturan dan kebijakan mengenai pemanfaatan lestari hutan mangrove \\
\hline & Kabupaten & & 2. Melindungi ekosistem pesisir yang rawan erosi/abrasi dan bencana alam \\
\hline & & & 3. Memperkuat kelembagaan pengelolaan ekosistem mangrove \\
\hline \multirow[t]{3}{*}{3} & DKP & 2 & 1. Menentukan kebijakan dalam pengelolaan ekosistem mangrove \\
\hline & Provinsi & & 2. Membantu pihak DKP Kabupaten dalam \\
\hline & & & 3. Konservasi, sosialisasi, memfasilitasi pemanfaatan ekosistem. \\
\hline \multirow[t]{2}{*}{4} & $\mathrm{KLH}$ & 2 & $\begin{array}{l}\text { 1. Memperkuat lembaga pengelola mangrove derah sebagai wadah komunikasi dan } \\
\text { koordinasi pengelolaan ekosistem mangrove }\end{array}$ \\
\hline & & & $\begin{array}{l}\text { 2. Mendorong kegiatan pendidikan, pelatihan dan penyuluhan tentang pengelolaan } \\
\text { ekosistem mangrove }\end{array}$ \\
\hline \multirow[t]{3}{*}{5} & Bappeda & 4 & $\begin{array}{l}\text { 1. Mengkoordinasikan forum lokal kemitraan pemangku kepentingan dalam } \\
\text { lembaga pengelola }\end{array}$ \\
\hline & & & 2. Resolusi konflik antar pemangku kepentingan \\
\hline & & & $\begin{array}{l}\text { 3. Menyusun petunjuk teknis terkait pengelolaan ekosistem mangrove sesuai kondisi } \\
\text { wilayah }\end{array}$ \\
\hline \multirow[t]{2}{*}{6} & Akademisi & 1 & $\begin{array}{l}\text { 1. Melakukan kajian - kajian keilmuan dalam rangka mendukung pengelolaan } \\
\text { ekosistem mangrove }\end{array}$ \\
\hline & & & $\begin{array}{l}\text { 2. Memberikan sharing pengetahuan, data yang terkait dalam pengelolaan ekosistem } \\
\text { mangrove }\end{array}$ \\
\hline
\end{tabular}


7 LSM

2

8 Pemerintah

Desa Lubuk

Kertang

9 Kelompok tani mangrove

Lubuk Kertang

10 Kelompok Nelayan

11 Petambak

12 Masyarakat sekitar

13 Pencari kepiting

14 Pencari tiram

15 Pencari kayu bakar

16 Kepolisian/ Kodim
1. Sebagai mitra pemerintah dalam pelaksanaan kegiatan pengelolaan ekosistem mangrove

2. Pengorganisasian masyarakat dalam inisiasi maupun implementasi pengelolaan

3. Memberikan masukan,data,informasi dalam pelaksanaan pengelolaan ekosistem mangrove

1. Menyediakan dan mengkoordinasikan forum lokal dengan pemerintah dalam pengelolaan bersama

2. Menengahi konflik sosial masyarakat dalam hal pemanfaatan mangrove

3. Menyampaikan informasi dari masyarakat ke lembaga dan sebaliknya

1. Kebijakan pengawasan dalam menjaga kelestarian ekosistem mangrove dari pengrusakan

2. Perencanaan dan implementasi kegiatan

3. Memberikan masukan,data,informasi terhadap pelaksanaan pengelolaan ekosistem mangrove

2 Kebijakan pengawasan dalam menjaga kelestarian ekosistem mangrove dari pengrusakan dan pemanfaatan sebagai nursery ground

2 1. Menjaga ekosistem mangrove

2. Melapor apabila terjadi kerusakan ekosistem mangrove

3 1. Menjaga ekosistem mangrove

2. Menjaga sanitasi dan kebersihan lingkungan

1. Menjaga ekosistem mangrove

2. Melapor apabila terjadi kerusakan mangrove

1. Menjaga ekosistem mangrove

2. Melapor apabila terjadi kerusakan mangrove

1. Menjaga ekosistem mangrove

2. Melapor apabila terjadi kerusakan mangrove

Pengaman peraturan/hukum

Sumber: data olahan

Proses pengawasan dan evaluasi yang hanya dilakukan oleh pemerintah dan tidak melibatkan semua para pemangku kepentingan membuat informasi mengenai perkembangan kondisi ekosistem mangrove saat ini hanya dimiliki sepihak dan kurang efektif dalam pengelolaan. Sehingga melalui adanya lembaga pengelola mangrove yang dibuat, dapat dilaksanakan forum pertemuan rutin bagi para pemangku kepentingan terkait perkembangan kegiatan pengawasan dan evaluasi terhadap sumberdaya. Proses pengawasan dapat dilakukan oleh para pelaku pemanfaat seperti petambak, kelompok tani, pencari tiram, pencari kepiting, dan pencari kayu bakar sambil memanfaatkan ekosistem mangrove tanpa merusak ekosistem. Nelayan mencari ikan di laut dan jika terdapat permasalahan dalam penyalahgunaan mangrove maka nelayan dapat melaporkan kepada ketua kelompok atau perangkat desa sehingga akan bersama-sama mengontrol ekosistem mangrove.

Pihak akademisi yang melakukan penelitian di ekosistem mangrove dapat melaporkan hasil penelitiannya sehingga dapat menjadi landasan dalam mengembangkan ekosistem mangrove tersebut. Jika pemerintah memiliki rencana pengembangan untuk mangrove maka semua pemangku kepentingan terhadap mangrove akan saling merapat untuk bersama-sama dalam menghijaukan dan melestarikan ekosistem mangrove. Pemerintah daerah melalui Bappeda dapat menjadi fasilitator dalam proses evaluasi terkait kewenangannya dalam mengkoordinasikan forum lokal kemitraan pemangku kepentingan dengan mengumpulkan para pelaku kepentingan. Pertemuan dalam forum pemangku kepentingan ini dapat diagendakan secara rutin dalam lembaga pengelola dengan kesepakatan semua pemangku kepentingan. Indikator keberhasilan dari berjalannya pengawasan dan evaluasi dengan baik yaitu terlaksananya kegiatan pengawasan mangrove oleh para pelaku pemanfaat dan terlaksananya forum pertemuan rutin diantara para pemangku kepentingan dalam lembaga pengelola mangrove.

Adanya model pengelolaan ekosistem co-management tidak hanya bertujuan meningkatkan dan memelihara keberadaan mangrove, namun juga bertujuan untuk meningkatkan pengetahuan masyarakat dan khususnya peningkatan kesejahteraan masyarakat dengan keberadaan mangrove. Dengan model co-management peran, tanggung jawab dan pemanfaatan dari tiap pemangku kepentingan dapat diakomodir dengan tetap memperhatikan kelestarian ekosistem mangrove.

\section{Simpulan}

Berdasarkan spektrum co-management yang disusun oleh Adrianto (2007) bentuk pengelolaan co-management di Desa Lubuk Kertang, Brandan Barat, Langkat saat ini masih berada pada tahap konsultatif yaitu pemerintah mulai mempertimbangkan pandangan lokal sebelum membuat keputusan. Namun hal ini belum efektif karena dalam kegiatan 
lain seperti penyusunan rencana pengelolaan, pelaksanaan program, pengorganisasian , pengawasan dan evaluasi masih belum melibatkan seluruh pemangku kepentingan dari pihak masyarakat. Oleh karena itu, masyarakat pemanfaat dan seluruh pemangku kepentingan lain harus dapat lebih ditingkatkan partisipasinya dalam kegiatan perencanaan, pelaksanaan, pengorganisasian, pengawasan dan evaluasi dalam pengelolaan ekosistem mangrove.

\section{Daftar Pustaka}

Adrianto. 2007. Pengantar Kepada Ko-Manajemen Perikanan. Pusat Kajian Sumberdaya Pesisir dan Lautan. Institut Pertanian Bogor. Bogor

Bengen, D. G. 2002. Ekosistem dan Sumberdaya Alam Pesisir. Pusat Kajian Sumberdaya Pesisir dan Lautan. Fakultas Perikanan dan Ilmu Kelautan. Institut Pertanian Bogor. Bogor.

Gunarto. 2004. Konservasi mangrove sebagai pendukung sumber hayati perikanan pantai. Balai riset perikanan budidaya air payau. Sulawesi Selatan. Jurnal Litbang Pertanian. 23(1) : 15 - 21.

Hadi, Sudharto. P. 2014. Artikel. Pesisir: Zona Harapan dibawah Tekanan.

Hadian, Pratama Hamzah. 2020. Konsep Co-Management dalam pengelolaan hutan mangrove di Kabupaten Langkat. Universitas Diponegoro, Semarang.

Irwanmay, 2004. Analisis Dampak Pengalihan Lahan Konservasi Hutan Mangrove Menjadi Lahan Pertambakan Terhadap Keadaan Sosial Ekonomi Nelayan di Kecamatan Tanjung Pura kabupaten Langkat. Skripsi Medan: Fakultas Ilmu Sosial. UNIMED.

Nair, R. S., Bharat, A., \& Nair, M. G. 2012. DPIRS Framework for Sustainable Development of, 2(4), 117-125.

Noble BF.2000.Institutional Criteria For Co-Management. Journal Marine Policy. 24(2000) : 69-77.

Nadira, Siti 2018. Analisis Tutupan Lahan Menggunakan Citra Sentinel 2 di Kawasan Pesisir Kabupaten Langkat. Tesis. Universitas Sumatera Utara.

Irwanmay, 2004. Analisis Dampak Pengalihan Lahan Konservasi Hutan Mangrove Menjadi Lahan Pertambakan Terhadap Keadaan Sosial Ekonomi Nelayan di Kecamatan Tanjung Pura kabupaten Langkat. Skripsi Medan: Fakultas Ilmu Sosial. UNIMED.

Wijanarko B. 2016. Kemungkinan Penerapan Co-Management Dalam Pengelolaan Ruang Terbuka Hijau Di Pantai Utara Kota Surabaya [Tesis]. Program Pascasarjana Magister Teknik Pembangunan Wilayah Dan Kota Universitasdiponegoro. Semarang. 